\title{
Low-cost method of the highly porous iron sintering
}

\author{
M. Kvíčala ${ }^{1 *}$, A. Hendrych ${ }^{2}$, M. Stamborská ${ }^{1}$, A. Volodarskaja ${ }^{3}$, K. Skotnicová ${ }^{1}$, T. Čegan ${ }^{1,4}$, \\ J. Juřica ${ }^{1}$ \\ ${ }^{1}$ Department of Non-ferrous Metals, Refining and Recycling, Vふ̆B-Technical University of Ostrava, \\ 17. listopadu 15, 70833 Ostrava-Poruba, Czech Republic \\ ${ }^{2}$ Department of Physics and IT4Innovations Centre of Excellence, V $\breve{S} B$-Technical University of Ostrava, \\ 17. listopadu 15, 70833 Ostrava-Poruba, Czech Republic \\ ${ }^{3}$ Department of Material Engineering, Vঙ̆B-Technical University of Ostrava, \\ 17. listopadu 15, 70833 Ostrava-Poruba, Czech Republic \\ ${ }^{4}$ Institute of Materials and Machine Mechanics, Slovak Academy of Sciences, \\ Račianska 75, 83102 Bratislava 3, Slovak Republic
}

Received 21 February 2014, received in revised form 31 March 2014, accepted 13 October 2014

\begin{abstract}
This paper reports a study of low-cost method relating to the preparation of well defined porous iron-based materials. We employed the technique where the impressed iron oxide powder is sintered. We changed the specific volume fraction of sodium chloride as a primary pore forming additive to achieve the total porosity up to $70 \%$ and effective/total porosity rate in a ratio of 0.89 with interconnected pores. The investigations of physical properties with respect to the particle size distribution, powder morphology, density, volume contraction and both effective and total porosity were carried out by laser diffraction (LD), pycnometric measurement, atomic force microscopy (AFM), scanning electron microscopy (SEM) and optical microscopy. Porous iron sintered electrodes represent a suitable alternative to the expensive nickel electrodes.
\end{abstract}

K e y w or d s: iron, sodium chloride, sintering, porosity, surface topography

\section{Introduction}

Porous iron and its oxides are of great scientific and technological importance. They are used in various application fields because of their low price, good mechanical and thermophysical properties. Those fields are for example magnetic materials [1], ethanol sensors $[2]$, gas sensors materials $[3,4]$, iron based catalysts [5], cathodes used in electrolysis of $\mathrm{CO}_{2}$ in a proton conducting membranes [6] and anodes in rechargeable lithium-ion batteries instead of graphite [7]. Porous iron sintered electrodes with high surface area represent a suitable alternative to the expensive nickel electrodes [8]. Moreover, porous iron can be used as a negative active nickel-iron and iron-air electrodes [9]. Economic aspects are crucial for evaluation of highly porous iron sintering usefulness. Highly porous iron and iron oxides based materials manufactured by inexpensive way represent perspective trend in up to date technical applications. Moreover, surface characteristics can be used for production quality control. In this paper we demonstrate effective and inexpensive method of the iron powder sintering by using sodium chloride as pores forming additive which allows to create highly porous material with a high fraction of effective pores.

As pores forming additive can be used magnesium [10], sodium chloride [11], saccharose [12], carbamide and even urea crystals [13]. In our work we decided to use $\mathrm{NaCl}$ as a cheap structure forming additive with favourable crystal size. One of the $\mathrm{NaCl}$ advantages is a wide temperature range when $\mathrm{NaCl}$ evaporates (up to $800^{\circ} \mathrm{C}$ ). Stamped porous iron specimen can be sintered in one step (separate pore forming additive removal is not necessary).

*Corresponding author: tel.: +420 597329 387; e-mail address: kvicalam@seznam.cz 


\section{Experimental methods}

Four specimens were prepared in total. Iron powder (Fe purity 99.9 wt.\%) used in this paper was produced by hydrogen reduction. The first specimen consisted of pure iron powder without any additives. The second specimen consisted of Fe powder mixed with $20 \%$ volume fraction of sodium chloride $(\mathrm{NaCl})$ as a pore forming additive. The third mixture consisted of $\mathrm{Fe}$ powder mixed with $40 \%$ volume fraction of $\mathrm{NaCl}$. The fourth mixture contained Fe powder with $60 \%$ volume fraction of $\mathrm{NaCl}$. Particle size distribution of the $\mathrm{Fe}$ powder was determined by laser diffraction (Fritsch Analysette 22) and $\mathrm{NaCl}$ crystal size distribution was determined by sieve analysis (Fritsch Analysette PRO $3)$. For the Fe powder morphology characterization was used the optical microscopy (Olympus SZX7). All specimens were isostatically stamped by $400 \mathrm{MPa}$ pressure using CIP EPS stamp (cold stamping). All the specimens were stamped in a cylindrical shaped resin form with internal diameter $20 \mathrm{~mm}$. It is necessary to emphasize that Fe powder with $60 \%$ volume fraction of $\mathrm{NaCl}$ could not be successfully stamped. Remaining three specimens were sintered in annealing oven (Clasic) at $1200^{\circ} \mathrm{C}$ for two hours. Temperature increment was $10^{\circ} \mathrm{C} \mathrm{min}{ }^{-1}$. Moreover, when $600^{\circ} \mathrm{C}$ were achieved, heating through period occurred $(1 \mathrm{~h})$. The main aim of the heating through period was to complete $\mathrm{NaCl}$ evaporation.

Sintering process was realized by using protection atmosphere (volume fractions were $95 \% \mathrm{Ar}$ and $5 \%$ $\mathrm{H}_{2}$ ). Density, volume contraction, effective, ineffective and total porosity were determined by pycnometric method (AccuPyc II 1340) and double weighting method. All specimens microstructure was evaluated by SEM (FEI QUANTA 650 FEG) and metallographic microscope Olympus SD12. Surface topography observations were performed by atomic force microscopy (AFM, NT-MDT, Ntegra Prima) operated in semicontact mode with Si cantilever tips.

\section{Results and discussion}

Fe powder morphology analysis revealed predominantly spongy shaped grains, which are characterized
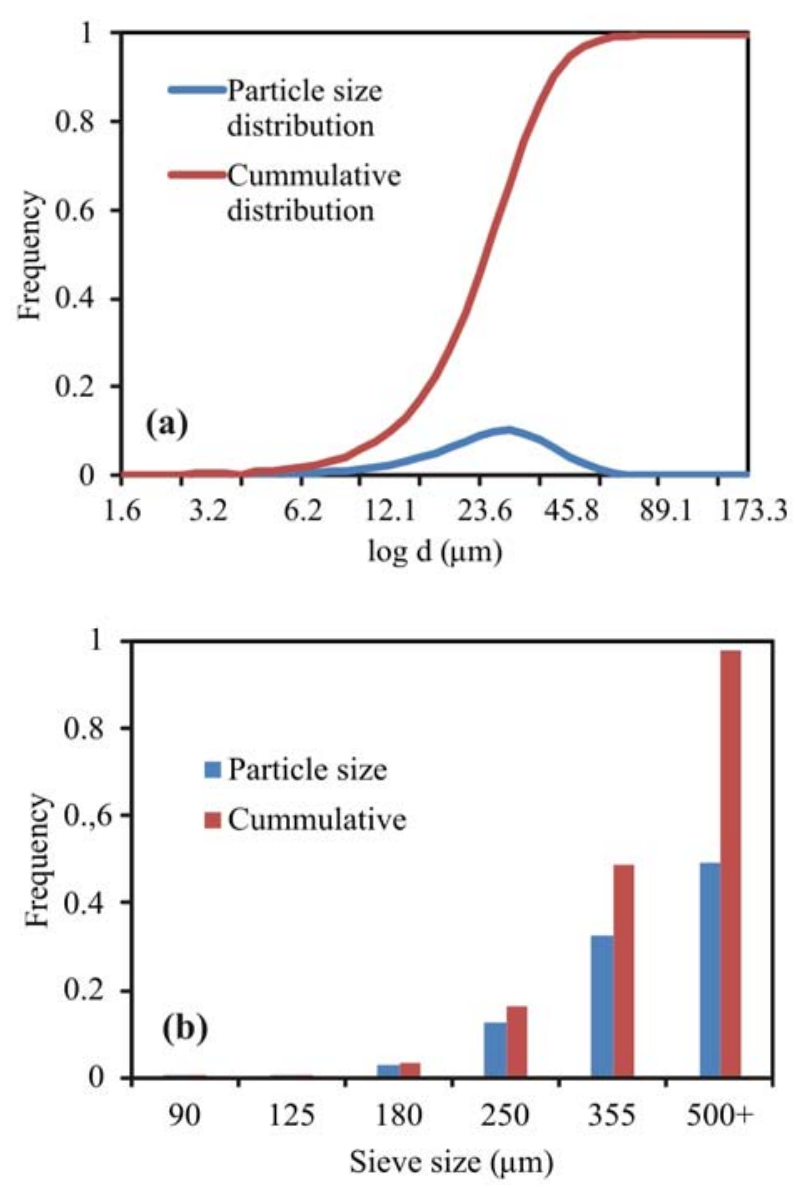

Fig. 1. Dependence of the particles frequency and cummulative distribution on logarithm of particle size for $\mathrm{Fe}$ powder (a) and sieve size for $\mathrm{NaCl}(\mathrm{b})$.

by irregular surfaces with many micropores. This observation corresponds with the Fe powder preparation method - hydrogen reduction. Suitable shape of the Fe particles allowed cold stamping of the specimens with $\mathrm{NaCl}$ volume fraction up to $40 \%$. Average particle size of the Fe powder was $24.2 \mu \mathrm{m}$. Both particle size distribution and cumulative distribution of the Fe powder and $\mathrm{NaCl}$ crystals are depicted in Fig. 1. It was observed that relatively short sintering period combined with sintering procedure mentioned above is suitable for the achievement of high porosity. According to

Table 1. Summarized variables obtained by pycnometric method and double weighting method ( $P_{\mathrm{e}}$ is effective porosity, $P_{\mathrm{i}}$ is ineffective porosity, $P_{\mathrm{t}}$ is total porosity, $\Delta V$ is volume contraction and $\rho$ is density)

\begin{tabular}{ccccccc}
\hline Specimen & $P_{\mathrm{e}}(\%)$ & $P_{\mathrm{i}}(\%)$ & $P_{\mathrm{t}}(\%)$ & $P_{\mathrm{e}} / P_{\mathrm{t}}$ & $\Delta V(\%)$ & $\rho\left(\mathrm{kg} \mathrm{m}^{-3}\right)$ \\
\hline $\mathrm{Fe}$ & 16.14 & 2 & 18.14 & 0.89 & 26.04 & 6390 \\
$\mathrm{Fe}+20 \% \mathrm{NaCl}$ & 34.15 & 12.46 & 46.6 & 0.73 & 33.58 & 4170 \\
$\mathrm{Fe}+40 \% \mathrm{NaCl}$ & 61.87 & 8.82 & 70.69 & 0.88 & 36 & 2290 \\
\hline
\end{tabular}




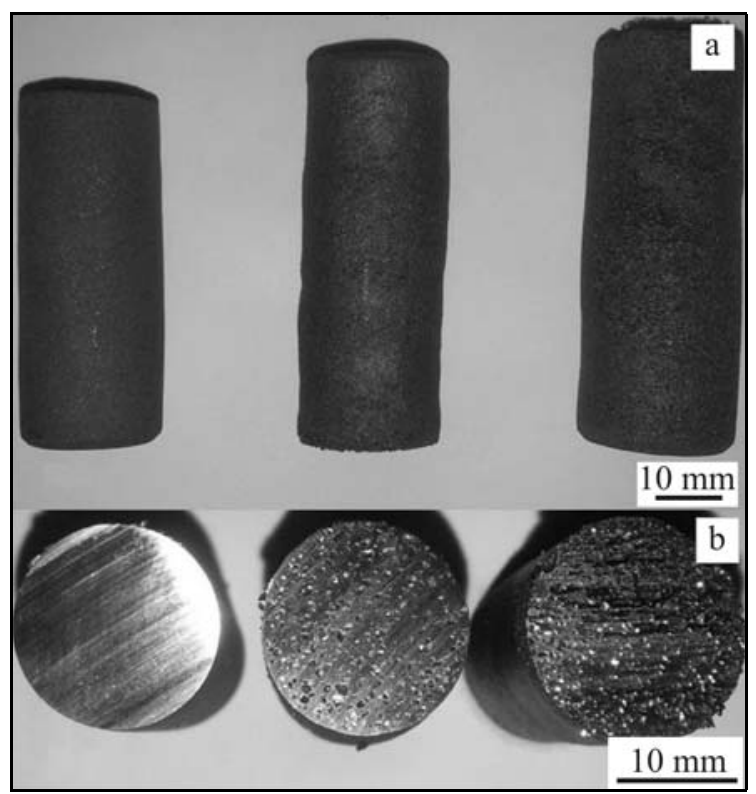

Fig. 2. Photography of the sintered samples side view (a) (pure $\mathrm{Fe}$ - left side, $\mathrm{Fe}+20 \% \mathrm{NaCl}$ - middle, $\mathrm{Fe}+40 \%$ $\mathrm{NaCl}$ - right side) and transverse cut of the samples (b) (pure $\mathrm{Fe}$ - left side, $\mathrm{Fe}+20 \% \mathrm{NaCl}-$ middle, $\mathrm{Fe}+40 \%$ $\mathrm{NaCl}$ - right side). pycnometric analysis it is possible to prepare iron specimens with total porosity $70.69 \%$. Variables obtained by pycnometric method and double weighting method are summarized in Table 1. For practical applications such as catalysts and cathodes the most important variable is an effective porosity that represents surface characteristics of the specimens. Specimen prepared from $\mathrm{Fe}+40 \% \mathrm{NaCl}$ demonstrated not only higher effective porosity than specimen prepared from $\mathrm{Fe}+20 \% \mathrm{NaCl}$, but also effective/total porosity rate was higher, see Table 1. Sintered specimens and their transverse cuts are presented in Fig. 2. Practical problem represents heterogeneity of the highly porous Fe specimens. During the preparation the powder mixtures have to be stirred carefully because of significant difference between $\mathrm{Fe}$ and $\mathrm{NaCl}$ densities. Problems with specimens homogeneity can occur if the specimens are not stamped in more steps. Anyway, repeated stamping is sufficient method to ensure acceptable specimens homogeneity. Microscopic evaluation revealed interconnected pores networks not only in the specimens that were sintered with pore forming additive (Fig. 2c,d), but also in the specimen which was sintered without any additive, see Fig. 2a,b. All spe-
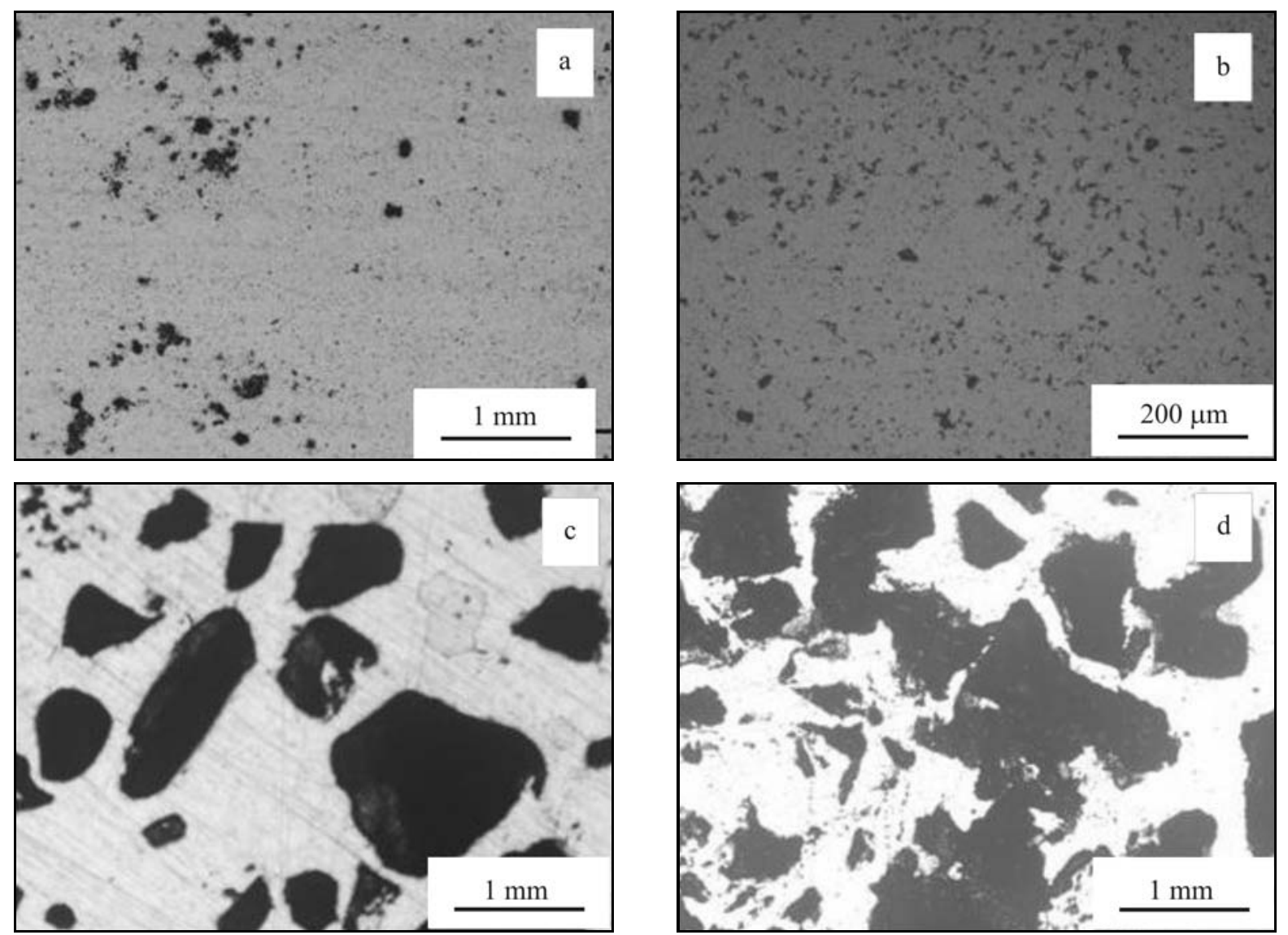

Fig. 3. Microscopic evaluation of macropores size and interconnections: sintered $\mathrm{Fe}(\mathrm{a}, \mathrm{b})$, sintered $\mathrm{Fe}+20 \% \mathrm{NaCl}(\mathrm{c})$ and sintered $\mathrm{Fe}+40 \% \mathrm{NaCl}(\mathrm{d})$. 

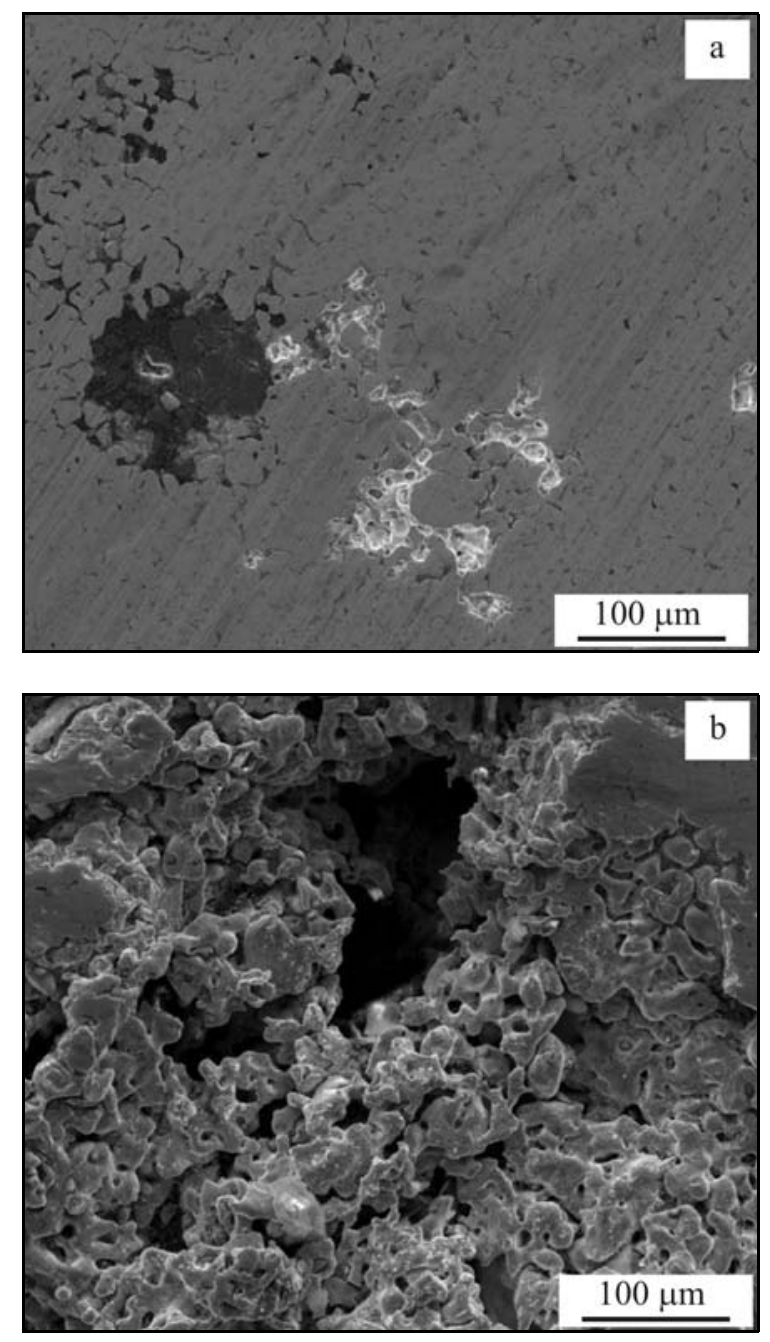

Fig. 4. SEM images of sintered iron specimens: Fe without pores forming additive (a) and $\mathrm{Fe}+20 \% \mathrm{NaCl}(\mathrm{b})$.

cimens were evaluated by SEM technique. Iron specimen sintered without pores forming additive revealed partially interconnected small pores with low depth profile. On the other hand, specimens sintered with $\mathrm{NaCl}$ addition exhibited not only well interconnected pores but also high depth profile. This high depth profile represents added value in electrochemical applications due to bigger higher specific surface. Moreover, all evaluated specimens did not show any significant cracks that could be associated with stamping and/or sintering process, see Fig. 4. Surface topography evaluation included 3D roughness, peak to peak variable and Hausdorf fractal dimension. These variables that characterize surface properties are important not only for catalysts with increased efficiency production, but they are also a suitable tool for verification of the production quality. While specimen sintered from pure Fe showed quite smooth surface, specimen sintered with $20 \%$ volume fraction of $\mathrm{NaCl}$ showed almost uniformly rough surface. Typical surface topography
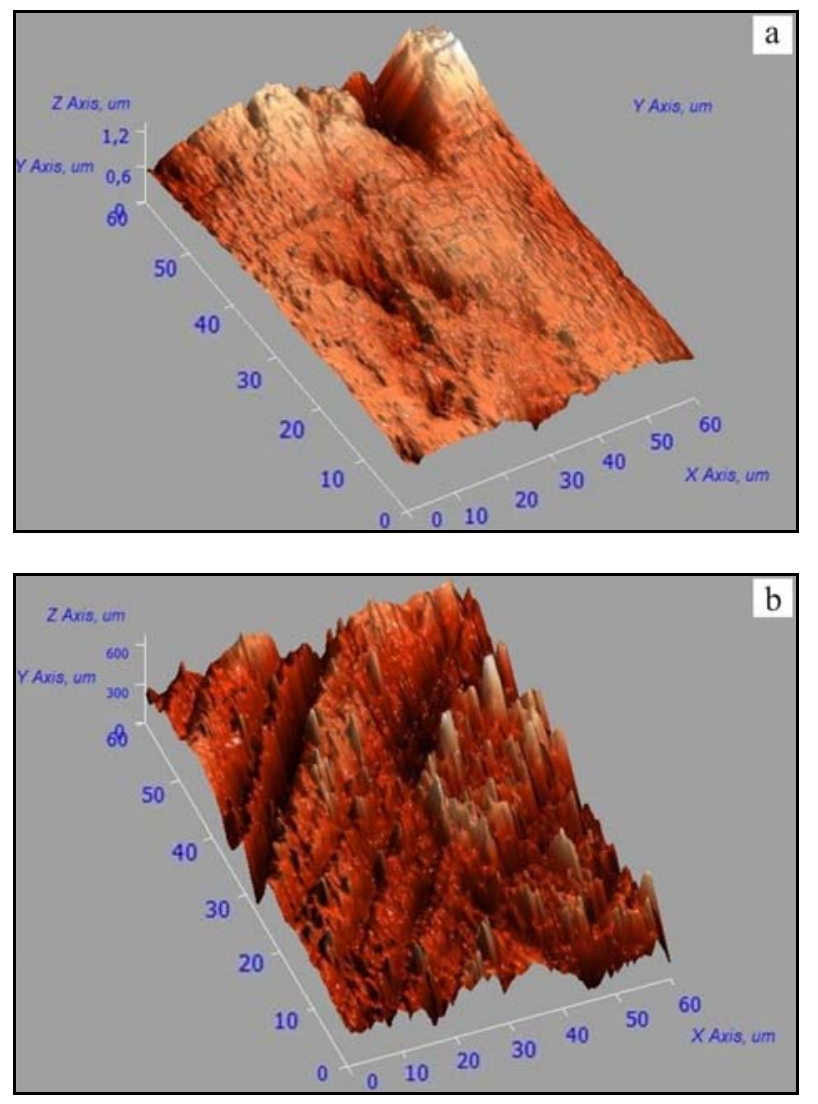

Fig. 5. Surface topography of sintered Fe specimens: Fe without pores forming additive (a) and $\mathrm{Fe}+20 \% \mathrm{NaCl}$ (b).

Table 2. Surface characteristics obtained from AFM analysis (PTP is peak to peak, $D_{\mathrm{H}}$ is Hausdorf fractal dimension)

\begin{tabular}{cccc}
\hline Specimen & 3D roughness $(\mu \mathrm{m})$ & $\mathrm{PTP}(\mu \mathrm{m})$ & $D_{\mathrm{H}}$ \\
\hline $\mathrm{Fe}$ & 0.066 & 0.455 & 2.58 \\
$\mathrm{Fe}+20 \% \mathrm{NaCl}$ & 0.376 & 2.621 & 2.65 \\
\hline
\end{tabular}

of the specimens sintered with and without structure forming additive is demonstrated in Fig. 5. AFM cannot be used in case of very rough surfaces (specimen with $40 \% \mathrm{NaCl}$ ). Anyway, AFM represents suitable method for highly porous surface analysis, although very fine pores forming additive has to be used in this case. The most important surface characteristics determined by AFM are summarized in Table 2 . All three variables presented in Table 2 are sensitive indicators of the surface topography. The most fundamental difference was observed in case of the 3D roughness. Also peak to peak variable revealed significant difference between the surfaces of Fe powder sintered with and without structure forming additive. 
Our results are in good agreement with conclusions of Ficker [14] who found out correlation between surface fractal dimension and material porosity.

\section{Conclusions}

In this paper it is demonstrated that $\mathrm{NaCl}$ represents a suitable structure forming additive for sintering of the iron powders. By using this method it was possible to get total porosity of approximately $70 \%$. Moreover, effective/total porosity rate was also high (0.89) and interconnection networks among pores were observed. It was confirmed that it can be an effective tool for porous materials production. Highly porous iron sintering by using $\mathrm{NaCl}$ as a structure forming additive represents an effective and low-cost method which can be used in the production of electrodes, sensors and catalysts. SEM technique revealed well interconnected pores with high depth profiles in case of iron specimens sintered with $\mathrm{NaCl}$ addition. Moreover, no significant cracks were detected. AFM allowed to characterize 3D surface roughness, fractal dimension and surface profile.

\section{Acknowledgements}

This paper has been elaborated in the framework of the project Opportunity for young researchers, reg. No. CZ.1.07/2.3.00/30.0016, supported by Operational Programme Education for Competitiveness and cofinanced by the European Social Fund and the state budget of the Czech Republic. This paper was created in the Project No. LO1203 "Regional Materials Science and Technology Centre - Feasibility Program" funded by Ministry of Education, Youth and Sports of the Czech Republic. This paper has been also elaborated in the framework of the project IT4Innovations Centre of Excellence project, reg. No. CZ.1.05/1.1.00/02.0070, by the Grant Agency of the Czech Republic (P205/11/2137) and by the grant reg. No. SP $2013 / 51$.

\section{References}

[1] Suresh, R., Prabu, R., Vijayaraj, A., Giribabu, K., Stephen, A., Narayanan, R.: Materials Chemistry and Physics, 134, 2012, p. 590. doi:10.1016/i.matchemphys.2012.03.034

[2] Wang, Y., Cao, J. L., Ju, M. G., Sun, G., Wang, X. D., Bala, H.: Materials Letters, 100, 2013, p. 102. doi:10.1016/j.matlet.2013.03.037

[3] Kim, H. J., Choi, K. I., Kim, K. M., Na, C. W., Lee, J. H.: Sensors and Actuators B, 171, 2012, p. 1029. doi:10.1016/j.snb.2012.06.029

[4] Wang, Y., Cao, J. L., Wang, S. R., Guo, X. Z., Zhang, J., Xia, H. J., Zhang, S., Wu, S.: The Journal of Physical Chemistry C, 112, 2008, p. 17804. doi:10.1021/jp806430f

[5] Castro, A. J. R., Soares, J. M., Filho, J. M., Oliveira, A. C., Campos, A., Milet, E. R. C.: Fuel, 108, 2013, p. 740. doi:10.1016/j.fuel.2013.02.019

[6] Ruiz-Trejo, E., Irvine, J. T. S.: Solid State Ionics, 252, 2013, p. 157. doi:10.1016/j.ssi.2013.05.021

[7] Wu, H., Du, N., Wang, J., Zhang, H., Yang, D.: Journal of Power Sources, 246, 2014, p. 198. doi:10.1016/j.jpowsour.2013.07.063

[8] Jaron, A., Zurek, Z.: Archives of Metallurgy and Materials, 53, 2008, p. 847.

[9] Periasamy, P., Babu, B. R., Iyer, S. V.: Journal of Power Sources, 58, 1996, p. 35. doi:10.1016/0378-7753(95)02274-0

[10] Kim, S. W., Jung, H. D., Kang, M. H., Kim, H. E., Koh, Y. H., Estrin, Y.: Materials Science and Engineering C, 33, 2013, p. 2808. doi:10.1016/i.msec.2013.03.011

[11] Kobashi, M., Miyake, S., Kanetake, N.: Intermetallics, 42, 2013, p. 32. doi:10.1016/j.intermet.2013.04.017

[12] Jakubowicz, J., Adamek, G., Dewidar, M.: Journal of Porous Materials, 20, 2013, p. 1137. doi:10.1007/s10934-013-9696-0

[13] Wenjuan, N., Chenguang, B., Guibao, Q., Qiang, W.: Materials Science Engineering A, 506, 2009, p. 148. doi:10.1016/j.msea.2008.11.022

[14] Ficker, T.: Theoretical and Applied Fracture Mechanics, 50, 2008, p. 167. doi:10.1016/j.tafmec.2008.07.004 